\title{
A qualitative investigation into nurses' perceptions of factors influencing staff injuries sustained during physical interventions employed in response to service user violence within one secure learning disability service
}

\begin{abstract}
Aims: The aim of the study was to examine learning disability nurses' perceptions of incidents involving physical intervention, particularly factors contributing to injuries sustained by this group.
\end{abstract}

Background: This article reports on a qualitative study undertaken within one secure NHS Trust to respond to concerns about staff injuries sustained during physical interventions to prevent incidents of service user violence from escalating out of control. The context of the study relates to increasing debate about the most effective approaches to incidents of violence and aggression.

Design: A qualitative research design was utilized for the study.

Methods: Semi-structured interviews were undertaken with 20 participants, 2 from each of the 10 incidents involving staff injury sustained during physical intervention.

Results: Four themes were produced by the analysis, the first, knowledge and understanding, contextualized the other three, which related to the physical intervention techniques employed, the interpretation of the incident and the impact on staff. 
Conclusion: Service user violence consistently poses nurses with the challenge of balancing the need to respond in order to maintain the safety of everyone whilst simultaneous supporting and caring for people with complex needs. This study highlights the need for further exploration of the contributory factors to the escalation of potentially violent situations.

Relevance to clinical practice: Services may have good systems in place for responding to and managing service user violence but appear less effective in understanding the reasons for and developing strategies to prevent violence occurring.

\section{Summary box}

'What does this paper contribute to the wider global clinical community?'

- The escalation phase in violent incidents requires more thorough analysis in terms of recognition of how it might develop and understanding how de-escalation could be more effective.

- The significant attention placed on the appropriateness of the physical intervention system adopted appears sometimes to distract from analysis of the preceding circumstances.

- The physical and psychological consequences of being involved in a violent incident are well known but perhaps not so well understood by both services and staff.

Key words: Learning disability nursing; physical interventions; staff injuries; violent incidents 


\section{INTRODUCTION}

The use of physical interventions in the care of vulnerable people, such as those with learning disabilities, autism, dementia, psychosis or borderline personality disorder, has attracted increased interest over the last few years (DH, 2012; MIND, 2013) culminating in a recent guide for commissioners and employers with the aim of minimising restrictive practices $(\mathrm{DH}$, 2014). This developing concern followed the publication of a National Institute for Health and Clinical Excellence (NICE) guideline (2005) responding to escalating anxiety about the ethics and legalities of the dominant control and restraint system and the need for alternatives (e.g. Baker \& Bissmire, 2000). The issue of violence involving people with learning disabilities and/or mental health difficulties as perpetrators is an international one (Duxbury et al. 2008), and there is an impetus to reduce physical intervention, albeit not without fears of a subsequent increase in assaults on and injuries sustained by care workers (Liberman, 2006). Since such injuries outweigh those sustained by service users with learning disabilities by as much as four times (Johnson, 2012), research is both warranted and imperative (Moylan \& Cullinan, 2011).

This paper reports on a collaborative study between a secure NHS Trust (the organisation) and a University research team, both based in the north of England, to examine nursing staff perceptions regarding physical intervention techniques in managing incidents of violence by service users with a learning disability during which staff injury occurred. The physical intervention system examined combines Creative Intervention Training in Response to Untoward Situations (CITRUS), accredited by the British Institute of Learning Disabilities, a non-pain compliant response to the aggression of some service users, with Enhanced Physical 
Intervention (EPI), a more robust response to the more serious aggression of a smaller number of individuals.

\section{BACKGROUND}

Whittington et al (2012) investigated patterns of aggressive behaviour amongst service users with a mental illness and the responses of staff over a five-year period. These authors suggested that as staff and service users become more familiar with one another, the need for physical intervention diminishes and aggressive incidents are usually de-escalated safely through non-physical intervention. Similarly, care workers with less developed skills and knowledge, who also lack experience of working with particular service users, are likely to encounter difficulty recognizing factors specific to an individual during the build-up to an incident of violence (Turner \& Clarke, 2009). These elements are significant in enhancing confidence in defusing potentially violent situations through non-physical intervention, and, perhaps of equal importance, have a positive impact on relationships between staff and service users (Cowin et al., 2003).

The term learning disability comprises three interrelated criteria, significant impairment of intelligence, significant impairment of adaptive/social functioning, and age of onset before 18 years old (British Psychological Society, 2000). Successful resolution of potential aggression requires that staff comprehend how such criteria influence an individual's interpretation of a situation, particularly the centrality of trust to the professional relationship and how this contributes to successful de-escalation (Fish \& Culshaw, 2005). A mutually trusting relationship, however, is difficult to achieve with individuals with difficult backgrounds and a history of violence, particularly if staff knowledge and skills are insufficient. This is complicated further by the tension between undertaking appropriate training to participate in 
physical intervention safely and seeking to fully exploit the possibilities of successful deescalation through non-physical techniques (NICE, 2005). Physical intervention refers to 'any method of responding to behaviour that involves some degree of direct physical force to limit or restrict movement or mobility' (Harris et al., 1996:2). The new wave of approaches to physical interventions for people with learning disabilities gathered pace during the first decade of the century, with concerns about human rights, avoiding pain, and ensuring person centred care becoming more influential (Allen, Doyle \& Kaye, 2002). The CITRUS approach is representative of this development, and was designed specifically for those with a learning disability living in secure conditions; it employs both breakaway techniques to protect staff against physical assault and non-pain-compliant holding techniques in standing, sitting and lying positions. This system is coupled with an approach (Enhanced Physical Intervention) designed to secure holds in the event of more purposeful violence.

Investigations into the impact of physical interventions on service users far outweigh those relating to staff, one observer emphasising the peculiarity of the staff voice being either peripheral or absent from the discussion (Edwards (1999). Hawkins, Allen and Jenkins (2005) found that the staff experience of physical intervention was largely, but not entirely negative, with positive regard for a service user's feelings throughout, a high degree of emphasis on appropriate technical application and subsequent self-debriefing to reduce the negative impact. Physical interventions carry a risk of injury for all those involved and in some circumstances can provoke aggressive behaviour (Powell et al. 1994), but injuries are generally more common among staff than service users. The proportion of physical intervention episodes in mental health settings resulting in staff injuries vary from $12 \%$ (Southcott \& Howard 2007) to as high as 40\% (Dowson et al. 1999), whilst intervention episodes resulting in service user injuries ranged from 5-7\% (Southcott, Howard \& Collins, 
2007 ) to $18 \%$ (Leggett \& Silvester 2003). A survey of nurses also reported more injuries among staff and that their injuries were generally more serious than those of service users (Lee et al. 2003).

There is little evidence to imply causal factors for such variation in violent incidents, physical intervention and subsequent staff injuries, within mental health settings. However, an elevated risk of conflict has been linked with certain characteristics of service users. For example, Bowers at al., (2014) posited that conflict is correlated with younger males and people who are diagnosed with schizophrenia. Interestingly, there is also evidence to suggest that service users who need to be transferred from a prison setting to the NHS for treatment relating to a mental illness are often delayed or not diagnosed quickly, thus not being cared for appropriately (Reed, 2003). The situation for people with a learning disability is equally, if not more, difficult as they are often vulnerable to bullying and victimisation, whilst also being exposed to a culture of aggression within the prison environment (Rickford \& Edgar, 2005).

\section{METHODS}

\section{Research design}

A qualitative research framework was adopted since it was information about nursing / care staff perceptions of the incident, how it was responded to, and the effectiveness of the approach that was of interest to the researchers.

There were 3 objectives of the study:

1. To explore the perceptions of learning disability nurses / care staff in relation to contributory factors to staff injuries sustained during incidents involving physical intervention. 
2. To examine how the circumstances surrounding injuries sustained relate to the process of physical intervention.

3. To ascertain how staff injuries are sustained during incidents involving physical interventions and explore perceptions of the effects.

\section{Data collection}

A series of semi-structured interviews were undertaken with staff involved in 10 specific incidents of physical restraint over a 3-month period (i.e. 2 staff from each incident, a total of 20 participants), analysis of the incident forms (i.e. recordings of specific details), and analysis of case note material relating to the service user (i.e. background and build-up to incident). This paper provides an analysis of the interview data only, with findings from the other sources of data collection planned for a later article.

\section{Participants}

Qualified and unqualified nursing staff (one of each from every incident studied) involved in specific incidents of service user violence, whereby an injury was sustained by at least one member of the physical interventions team. The injury may have been incurred at different points in the intervention process i.e. before, during the incident or in any subsequent reescalation. Information about participant professional background, including physical intervention training, is provided in table 1.

Insert table 1 here

\section{Ethical issues}


Ethical approval was successfully sought from the University Faculty Research Ethics Committee and the Research and Development Committee of the NHS Trust. Application to the local R\&D office was also satisfied through the Integrated Research Application System (IRAS). The primary issues to satisfy unsurprisingly related to the provision of informed consent, maintenance of confidentiality, response to potential participant distress and safe storage of information.

\section{Data analysis}

A thematic analysis (following Braun \& Clarke, 2006) of the interview transcripts was undertaken, which involved simultaneous immersion in the data by all researchers, systematically searching for codes and categories, and the eventual production of relevant themes. The qualitative software package MAXqda was employed to assist the analysis, particularly useful in the storage and subsequent organization of the data (Richards, 2009), and facilitating the necessary structure to enhance rigorous analysis.

\section{Limitations}

The study was conducted with a representative but small number of participants within one fairly large NHS Trust encompassing low and medium secure care over a relatively short period of time, so generalisation is necessarily difficult.

\section{RESULTS}

Four themes were generated from the analysis:

- Knowledge and understanding

- Interpretation of the incident

- Physical intervention techniques 
Q refers to qualified nursing staff and $\mathrm{U}$ refers to unqualified nursing staff.

\section{Knowledge and understanding: 'de-escalation is the biggest skill going'}

There was a clear recognition amongst participants as to the significance of de-escalation in preventing a crisis and the subsequent need for physical intervention. This was combined with the need to judge accurately the appropriate time to engage in a more direct way with the individual. Effective verbal and non-verbal de-escalation techniques along with an inherent awareness of the service user and their needs/likes and dislikes were considered essential:

'...I always say to people de-escalation is the biggest skill going, you know, if we can get it at that point, hopefully we won't have to go into the intervention' $(Q 5$, female)

Participants emphasized the importance of building and maintaining meaningful professional working relationships with service users, significant for both de-escalation and avoiding intervention. This was particularly important with regard to individualizing care, understanding how best to approach the individual, which skills and techniques would be most valuable, and awareness by the service user that they were being well supported and understood:

'...I would try and give them time... if you just run in you know you're going to make that situation worse' (U10, male)

The absence of prior knowledge of the individual contributed to a lack of preparedness about the situation being encountered, particularly how best to de-escalate and prevent an exacerbation of already difficult circumstances. The possible consequences are made abundantly clear in the following quote: 
'...it was only my third day of working on there; I'd only met the lady twice...the other member of staff I was working with didn't know her either...I went to physically restrain her; both of us obviously didn't know what technique she was wrote up for, what de-escalation worked best for her, didn't know her risks, so she managed to bite me on the arm' (Q10, female)

Participants talked about the complexities of the service user group and the role this plays within potentially crisis situations. In conjunction with knowing the person individually, participants felt that an inherent understanding of learning disability and other co-morbid diagnoses was of high importance, particularly mental health problems and autism. Participants spoke about this in relation to having staff on the wards, who knew the service users, rather than unknown bank or agency staff:

'...you wouldn't want the ward to go to a level where there's people who don't know the clients....we've also got people with autism you know, who've got particular needs around the familiar and a routine...one particular man who, if he doesn't know you, you know, he doesn't trust you' (Q5, female)

In terms of the training in physical intervention techniques, although participants felt it was worthwhile, again the aspect of knowing and understanding people and their needs/diagnoses was perceived as equally important:

'...I found the training very good, it did give me a good insight...but I think a lot of it is once you actually get working on the wards, that's when you start learning because you need to know the ladies or men, because each one is a totally different personality' (U10, male)

\section{Interpretation of the incident: 'there was no trigger noticeable'}

Nurses sometimes considered the incident to have occurred spontaneously with no obvious build-up or clearly evident contributory factors: 
'it was very impulsive behaviour... my eyesight must have just gazed away from the person who I was with and when I turned back, she's grabbed hold of the client across the table by the hair' (Q6, male)

'She was fine; she was fine on here all morning... and then as soon as it came to meds, she just went, she just went for the grab...the nurse in charge got her ear pulled and I just hurt my elbow; there were no, like, major injuries' (U7, male)

This seeming absence of identifiable antecedents, furthermore, added a degree of complexity to the situation, exacerbating uncertainty, diminishing personal confidence, fear of the consequences of violence, exposing those who found such situations particularly challenging: '...however, when you've got no triggers I think people find it very difficult. I've had somebody who cannot do it, just had a drink thrown at her and somebody else who's been kicked from behind who...weren't expecting it, and that seems to affect people more and it does knock people’'s confidence' (Q6, male)

Unpredictability, with some individuals, was considered almost a defining characteristic, the possibility of violence never far away, yet the trigger might be there, lying just beneath the surface. The following quote, for example, contradicts itself, reflecting perhaps the problematic nature of differentiating an observable trigger from the subtler area of knowing the person:

'...there was no trigger noticeable, you know, all day she'd not been.... she could have gone either way but that's most days with her to be fair. And she got real giddy which is one of her triggers. Like I say, threw this book at me, threw items at me in the lounge, but she doesn't have a lot in the lounge so the stuff she was throwing was like a cushion and stuff that weren't going to hurt me, and then I managed to, like, dodge past her' (U8, female)

Sometimes, though, incidents had a clear history and the deterioration into violence could be described with insight; the following quotes, for example, suggest an element of inevitability 
combined with an approach demanding of empathy rather than provocation, however unintended:

'...tensions had been building up between two gentlemen for a while, something to do with cooking.... how a chicken was cooked.... and it all blew up' (Q1, female)

'sometimes I think if somebody's upset, I think sometimes you're better to try and talk to them and say 'is there anything I can do to help?', you know, and just basically show a bit of sympathy for them rather than say 'well, this isn't acceptable' (Q1, female)

\section{Physical intervention techniques: 'he comes running towards you'}

Two strands of discussion were threaded through participant accounts of physical interventions, the first, combating disparities in relation to weight and size, which might compromise the employment of the CITRUS and enhanced models, and secondly, the value and appropriateness when deployed in real life circumstances. Despite the rhetoric of size being irrelevant if techniques are employed effectively, it was, nevertheless, considered significant and sometimes influential by both male and female participants:

'... when you've not got the physical body capacity to get hold of somebody who's like 2 foot taller than you, and whose arm doesn't fit your grip, you know...you're not physically able to do it even though your techniques are the same as anybody else's and with the men, they tend to be quite big' (Q7, female)

Participants felt that this wasn't reflected or couldn't be captured within the simulated incidents/training as the techniques were very much staged and all in slow motion for the purpose of training. The unpredictability of the real-life situation was likely to cause concern when combined with concerns about weight/height and size in general, which could make the techniques more problematic to deploy and result in a less effective intervention: 
'...the training that you do, it's very measured and you go down on one knee... and I think sometimes when you're actually in that situation, you know, that that person isn 't fighting and isn't a strong person, with adrenaline; it's a lot different to what you will learn in training and I think everybody would agree with that, that's the difficulty' $(Q 4$, female $)$

The participants articulated that training is not always representative when deployed in aggressive, adrenaline fuelled situations on the wards:

'...I mean a lot of them, pretty much all the CITRUS techniques, you can only use them if the person is compliant, but obviously if you're being attacked by somebody, they're not going to be compliant are they?...I mean it might be with certain individuals but the ward I am on it's impossible to do that because when he's coming, he comes running towards you and his arms will be flying, so you can't...There's no chance of getting somebody down like that...when actually doing a technique on a person in training, that person will stand out with their arms out wide and actually on a ward when you're dealing with someone who's aggressive and wants to hit you, they're not going to come walking towards you with their arms out wide are they?'(U4, male)

Some participants also felt that the immediate use of enhanced physical intervention in some, extremely aggressive situations would be more beneficial than performing CITRUS in the first instance. The justification for this seemed to be related to an increased likelihood of staff sustaining physical injury if the intervention technique was perceived as inadequate to safely manage the level of aggression:

'...the kick backwards caught his [staff member] knee and knocked his knee cap, well three centimetres out of place. He's got that now for ever, for life....but if we'd have been walking in 'enhanced' he would never have been able to struggle... we were never informed to do that because as they say, to use the minimum as required...I'd have had the enhanced to start with, purely because it safer for staff' $U 3$, male () 
The final quote in this theme addresses the complexity of physical intervention use, with issues of assessing the situation accurately, comprehending the individual, the level of aggression, and the appropriateness of the choice of approach all coming to the fore:

'...if someone was coming at me with a hammer, I would more likely try and get a dining room table between me and them rather than, kind of, like, go and intervene with them ... a lot of it depends on the client, depends on the intensity of the aggression, depends on the intent. Once you get into the position for CITRUS, with a lot of our clients it is very effective. Some of the clients, using CITRUS is absolutely useless, you might as well not bother' (Q3, female)

\section{Impact on staff: 'I was completely devastated'}

The impact of being assaulted was complicated, irrespective of experience, something to be anticipated, almost part of the job role:

'I mean it's not good obviously, well it shouldn't be happening but then again, before you come here I think you do kind of have a mind-set that you probably will have to deal with some sort of aggression' (U9, male)

Participants described being involved in an incident and being assaulted as inculcating feelings of frustration and distress, emphasising the effect on mental well-being. Inherent in this frustration is also a sense of letting down peers on a busy ward with few staff:

'...I hate taking time off, I was absolutely devastated; I mean, the ward...it was really busy... it was very, very upsetting on so many levels for me, it made me realise how being assaulted affects not just your physical self but your mental self' (Q7, female)

'...nothing I have done warrants me getting assaulted and it's very frustrating and it's very distressing when it does happen' (Q6, male) 
Interestingly, one participant also talked about how being involved in incidents result in them questioning their practice and often blaming themselves about how they had handled a situation:

'...you get verbally abused every day...you are like saying 'was it my fault [the assault], have I done something to upset her?' You kind of go over it in your head' (U2, female)

The expectation of a certain amount of violence and abuse was contextualized by the evolving purpose of the service, with increased uncertainty about the individuals being cared for, the changing levels of aggression and potential consequences providing different challenges:

'...you've got people coming into the service that have been transferred from prison or the community through the courts, or whatever. Then you've got those sort of people with a lot of their own issues, unsettled, frightened, might be the first time they've come onto a unit like this and it might be that they've come from prison so they're very aggressive and they come with the pretence that they've got to fight for anything that they want' $(Q 7$, female)

\section{DISCUSSION}

The four themes, knowledge and understanding, interpretation of the incident, physical intervention techniques, and impact on staff, are clearly inter-related. There was a consensus amongst participants, unsurprisingly, with regard to the importance of knowing the service user, understanding how they might react to vicissitudes and having a good awareness of the particular approach to managing any deterioration in behaviour. Revelations about how an incident was interpreted, however, suggested a lack of knowledge about the build-up and identification of the particular trigger. There was a suggestion that staff could occasionally exacerbate an incident through rigidity of response or placing a little too much emphasis on behavioural signs rather than tangible reasons for distress. Only on one occasion, for 
example, was there acknowledgement that tensions between service users had reached a level where violence was a plausible consequence. This brings to mind Knight's (2011) finding that, whilst examining precursors to restraint, staff were sometimes insufficiently observationally skilled to be able to intervene effectively in the escalation phase. Analysis during the escalation phase is intrinsic to any physical intervention system and participants were clear that it was integral to both methods of physical intervention employed in the organisation. The transition from verbal to physical responses to aggressive behaviour remains a challenging question (Steinert et al., 2010) and should be both graduated and proportionate to benefits and risks (Steering Committee on Bioethics of the Council of Europe, 2005). The uncertain and sometimes contradictory evidence around knowing the individual, the nature of his or her learning disability, and possible triggers for violent behaviour provide a cause for concern. Nurses believed in stability being strongly linked to knowing the individual, yet were not always able to identify how an incident had developed, perhaps too often citing unpredictability and spontaneity. This is illustrative, perhaps, of Kontio et al (2010)'s conclusion that nurses need to respond at a deeper level to the reasons for violent behaviour, with greater emphasis on alternatives to restraint.

The primary concerns expressed by participants revolved around the practicalities of using physical intervention, particularly concerns about the size of an individual and relating techniques to the reality of a situation once violence had occurred. The CITRUS system, which attracted the most criticism, yet was also vigorously defended by some, constitutes a form of what Winship (2006) refers to as 'gentle restraint' (p.55), and centres on wellestablished principles in learning disability care, including positive behavioural support, individualized interventions based on need, positive communication and person centred care. The considerable amount of thought and regular adjustment to the organisation's physical 
intervention system was clearly accentuated in participant accounts, concerns about safety paramount, and staff being thoroughly prepared and trained fully addressed. The fusion of CITRUS and Enhanced Physical Interventions reflected the organisation's concern to include the spectrum of possible interventions, at least those with a physical contact dimension, something not always fully considered by services (Lancaster et al., 2008). The effectiveness of physical interventions as a means of reducing the number and severity of incidents, however, is difficult to accurately determine, with some suggesting that training makes no significant difference (Laker, Gray \& Flack, 2010). There was, furthermore, a marked absence of discussion around how non-physical alternatives could contribute to minimizing physical intervention, particularly during the crucial escalation phase, which can, of course, be of prolonged duration. Participants expressed clear understanding of individual roles during the intervention process, and were rarely critical of colleagues once the decision had been taken, the Blick (personal alarm system) operationalized, and physical intervention implemented. They sought effectively to safely and methodically immobilize the individual with the clear ultimate aim of restoring safety in the clinical environment (NICE, 2005). The difficulty appears twofold, utilizing more effectively the knowledge and understanding of the individual service user in an attempt to prevent a situation deteriorating into violence, and fully understanding and acknowledging the consequences of the incident and how it might contribute towards enhancing analysis of violence in the context of learning disability.

There was a certain tension between recognizing that violence shouldn't be part of one's working life, yet acknowledging that some verbal abuse and even physical assault was inevitable. This reflects recent findings suggesting learning disability nurses, in particular, regard service user violence with an enhanced degree of tolerance (Lovell \& Skellern, 2013). Staff found the consequences of violence extremely disturbing, both through the physical 
effects, which could be severe, but also in terms of the psychological impact, which could be prolonged. Concerns about the effects of physical intervention on service users were not directly addressed in this study, though research suggests as many as half of those restrained to be distressed a week later (Frueh et al., 2005). Nurses frequently emphasized the importance of relationships with service users, but perhaps knew the people they were nursing less well than they would have liked. It seems possible that they place great emphasis on accepting service users as individuals but need to continue to learn to develop the requisite knowledge to respond effectively to the needs of service users with increasingly complex needs (Lovell et al., 2014). The impact of violence appeared to take many nurses by surprise, yet is well established in the literature; services need, perhaps, to consider changing training needs, particularly around the process of escalation and reading changes in individual behaviour, maybe over several days, more accurately.

Organisations caring for individuals with a learning disability and a propensity for violence, according to this study, seek to provide the best care possible within the resources available, and the conjunction of the two systems of physical intervention sought to minimize injury and resolve violent situations quickly and effectively. The system adopted accorded with Robertson et al (2012), who note that best practice tends to be sought primarily through anecdotes from clinical practice rather than devising an approach based on theory and empirical research. De-escalation, for example, is often described in terms that fail to acknowledge that the escalation to violence might take a few seconds or several hours (Richter, 2006). Violence has been described as an interactive process led by a pattern where negative emotions increase and rationality decreases (Leadbetter \& Paterson, 1995). Many individuals with a learning disability, particularly when autism is an additional factor, experience considerable anxiety, and when this is coupled with a misinterpretation of a 
situation as a consequence of cognitive problems, the likelihood of violence increases. In other words, acute anxiety and diminished rationality combine with sometimes extremely distressing consequences. Davies \& Frude (1993) emphasize the importance of how a situation is appraised plus the perceived acceptability of aggression as the key factors in the manifestation of physical violence, and when these two factors are exacerbated further by powerful feelings of frustration, de-escalation becomes extremely complicated (Dix, 2008). The finding that nurses sometimes saw violence as occurring without triggers might indicate that there are times when the way in which some people with a learning disability interpret situations is unknown to those working with them. Similarly, the extent of their distress and anxiety might also go unnoticed, irrespective of the quality of relationship that staff may believe exists. There may be value in organisations examining current models of the escalation of violence, particularly when evidence based, and then incorporating those elements of learning disability, such as cognitive interpretation and feelings of anxiety, to contribute to and enhance our understanding of circumstances likely to result in violence.

\section{CONCLUSION}

This paper gives some insight into the experiences of nursing and care staff in an organisation which supports people with a learning disability in a forensic setting. Nurses are posed with the dichotomy of needing to respond to incidents of aggression and violence to maintain the safety of the person, their peers and the staff themselves, while at the same time getting to know and understand individuals with the purpose of supporting and nurturing them to move back to a community setting. Nurses come from the stand point of care and compassion and, as evidenced in this study, tend to feel perplexed when incidents escalate to the point where they or their colleagues have been injured while using techniques designed to restore calm to a potentially dangerous situation. This study highlights the need to continue to further explore 
the contributory factors to potentially aggressive situations and to support nurses to enhance their observation and de-escalation skills so that incidents requiring physical intervention rarely occur.

\section{Relevance to clinical practice}

- The escalation phase in violent incidents requires more thorough analysis in terms of recognition of how it might develop and understanding how de-escalation could be more effective.

- The significant attention placed on the appropriateness of the physical intervention system adopted appears to distract from reduced expertise in understanding the circumstances preceding their use.

- The physical and psychological consequences of being involved in a violent incident are well known but perhaps not so well understood by both services and staff.

- Increased emphasis on the importance of staff team consistency, particularly someone who knows each individual well.

- Greater understanding of the changes taking place within services in relation to service user characteristics and how these influence relations with staff. 


\section{REFERENCES}

Allen.D, Doyle.T and Kaye.N (2002) Plenty of gain, but no pain: a systems-wide initiative. In D.Allen (ed) Ethical Approaches to Physical Interventions: Responding to Challenging Behaviour in People with Intellectual Disabilities pp.219-232. Kidderminster: BILD

Baker.P.A and Bissmire.D (2000). A pilot study of the use of physical intervention in the crisis management of people with intellectual disabilities who present challenging behaviour. Journal of Applied Research in Intellectual Disabilities 13: 38-45

Bowers.L (2014) Safewards: the empirical basis of the model and a critical appraisal. Journal of Psychiatric and Mental Health Nursing 21: 354-364

Braun.V and Clarke.V (2006) Using Thematic Analysis in Psychology. Qualitative research in Psychology 3 (2) 77-10

British Psychological Society (2000) Learning Disability: Definitions and Contexts. Professional Affairs Board of the British psychological Society: Leicester

Cowin.L, Davies.R, Estall.G, Berlin.T, Fitzgerald.M and Hoot.S (2003) De-escalating aggression and violence in the mental health setting. International Journal of Mental Health Nursing 12(1) 64-73

Davies.W and Frude.N (1993) Preventing face to face Violence: Dealing with Anger and Aggression. Leicester: The Association for Psychological Therapies 
Department of Health (2012) Transforming Care: A national response to Winterbourne View Hospital London: DH

Department of Health (2014) A positive and proactive workforce: A guide to workforce development for commissioners and employers seeking to minimise the use of restrictive practices in social care and health. Bristol: Skills for Care

Dix.R (2008) De-escalation. In M.D.Beer, S.M.Pereira and C.Paton (eds) Frustration and Aggression. New haven: Yale University Press

Duxbury J., Hahn S., Needham I., et al. (2008). The management of aggression and violence attitude scale (MAVAS): a cross-national study. Journal of Advanced Nursing 62: 596-606

Edwards.R. (1999) The laying on of hands: nursing staff talk about physical restraint. Journal of Learning Disabilities for Nursing, Health \& Social Care 3: 136-143

Fish.R and Culshaw.E (2005) The last resort? Staff and client perspectives on physical intervention. Journal of Intellectual Disabilities 9(2) 93-107

Frueh.B.C, Knapp.R.G, Cusack.K.J et al. (2005) Special section on seclusion and restraint: Patients' reports of traumatic or harmful experiences within the psychiatric setting. Psychiatric Services 56: 1123-1133 
Harris.J, Allen.D, Cornick.M, Jefferson.A and Mills.R (1996) Physical Interventions: A Policy Framework. Kidderminster: British Institute for Learning Disabilities

Hawkins.S, Allen.D and Jenkins.R (2005) The use of physical interventions with people with intellectual disabilities and challenging behaviour-the experiences of service users and staff members. Journal of Applied Research in Intellectual Disabilities 18(1) 19-34

Johnson.P (2012) Staff injury arising from the use of physical intervention. Journal of Learning Disabilities and Offending Behaviour 3 (1) 35 - 43

Knight.M (2011) Precursors to seclusion or restraint: an analysis. Mental Health Practice $14(10) 14-20$

Kontio.R, Valimak.M, Putkonen.H, Kuosmanen.L, Scott.A and Joffe.G (2010) Patient restrictions: Are there ethical alternatives to seclusion and restraint? Nursing Ethics 17(1) 6576

Laker.C, Gray.R and Flach.C (2010) Case study evaluating the impact of de-escalation and physical intervention training. Journal of Psychiatric and Mental Health Nursing 1(3) 222228

Leadbetter.D and Paterson.B (1995) De-escalating aggressive behaviour. In B.Kidd and C.Stark (eds) Management of Violence and Aggression in Health Care. London: Gaskell 
Lee.S, Gray.R, Gournay, Wright.S, Parr. A.M and Sayer, J. (2003) Views of nursing staff on the use of physical restraint. Journal of Psychiatric and Mental Health Nursing 10(4) 425430

Leggett.J and Silvester. J (2003) Care staff attributions for violent incidents involving male and female patients: a field study. British Journal of Clinical Psychology 42(4) 393-406

Liberman P.L. (2006) Elimination of seclusion and restraint: a reasonable goal? Psychiatric Services 57: 576

Lovell.A, Bailey.J, Kingdon.A and Gentile.D (2014) Working with people with learning disabilities in varying degrees of security: nurses' perceptions of competencies. Journal of Advanced Nursing Article first published online: 7 FEB 2014 | DOI: 10.1111/jan.12362

Lovell.A and Skellern.J (2013) 'Tolerating violence': a qualitative study into the experience of professionals working in one UK learning disability service. Journal of Clinical Nursing $22(15-16) 2264-72$

MIND (2013) Mental Health Crisis Care: physical restraint in crisis. A report on physical restraint in hospital settings. London: MIND

Moylan.L.B and Cullinan.M (2011) Frequency of assault and severity of injury of psychiatric nurses in relation to the nurses' decision to restrain. Journal of Psychiatric and Mental Health Nursing 18: 526-34 
National Institute for Health and Clinical Excellence (2005) The Short Term Management of Disturbed/Violent Behaviour in In-Patient Psychiatric Settings and Emergency Departments - Guideline 25. London: National Institute of Mental Health

Powell.G, Caan.W and Crowe.M (1994) What events precede violent incidents in psychiatric hospitals? British Journal of Psychiatry 165: 107-112

Reed. J (2003). Mental health care in prisons. The British Journal of Psychiatry 182(4) 287288

Richards.L (2009). Handling qualitative data: A practical guide. Sage Publications

Richter.D (2006) Nonphysical conflict management and de-escalation. In D.Richter and R.Whittington (eds) Violence in mental health settings: Causes, consequences, management. New York: Springer

Rickford.D and Edgar.K (2005) Troubled Inside: Responding to the Mental Health Needs of Men in Prison. London: Prison Reform Trust.

Robertson.T, Daffern.M, Thomas.S and Martin.T (2012) De-escalation of limit-setting in forensic mental health units. Journal of Forensic Nursing 8: 94-101

Southcott.J, Howard.A and Collins.E (2002) Control and restraint training in acute mental health care. Nursing Standard 16(27) 33-36 
Southcott.J and Howard.A (2007) Effectiveness and safety of restraint and breakaway techniques in a psychiatric intensive care unit. Nursing Standard 21(36) 35-41

Steering Committee on Bioethics of the Council of Europe (2005) White Paper on the protection of the human rights and dignity of people suffering from mental disorders, especially those placed as involuntary patients in a psychiatric establishment. Council of Europe. http://www.ijic.org/docs/psychiatry.pdf Accessed 3rd August 2014

Steinert.T, Lepping.P, Bernherdsgrutter.R, Conca.A, Hatling.T, Janssen.W, Keski-Valkama.A, Mayoral.F and Whittington.R (2010). Incidence of seclusion and restraint in psychiatric hospitals: a literature review and survey of international trends. Soc Psychiatric Epidemiology 45: 889-897

Turner.K. and Clarke.D (2009) Aggression in intellectual disability: a new approach. Mental Health Review Journal 14(2): 28-36

Whittington.R, Leitner.M, Barr.W, Lancaster.G and McGuire. J (2012) Longitudinal trends in using physical interventions to manage aggression and self-harm in mental health services. Psychiatric services 63(5) 488-492

Winship.G (2006). Further thoughts on the process of restraint. Journal of Psychiatric and Mental Health Nursing 13: 55-60 


\begin{tabular}{|c|c|c|c|c|}
\hline Participant & Gender & Qualified & Length of service & Training \\
\hline Q10 & female & Yes MH & 6 years & Citrus + EPI \\
\hline U10 & male & No & 1.5 years & Citrus \\
\hline Q9 & female & Yes MH & 6 years & Citrus + EPI \\
\hline U9 & male & No /NVQ3 & 13.5 years & $\begin{array}{l}\text { Citrus + EPI } \\
*\end{array}$ \\
\hline Q8 & female & Yes LD & 5.5 years & Citrus + EPI \\
\hline $\mathrm{U} 8$ & female & No & 13 years & Citrus + EPI \\
\hline Q7 & male & Yes LD & 2.5 years & Citrus \\
\hline U7 & female & No & 3.5 years & Citrus + EPI \\
\hline Q6 & male & Yes LD ** & 19 years & Citrus + EPI \\
\hline U6 & female & No & 3 years & Citrus + EPI \\
\hline Q5 & male & Yes LD & 4 years & Citrus + EPI \\
\hline U5 & female & No & 24 years & Citrus + EPI \\
\hline Q4 & female & yes LD & 7 years & Citrus + EPI \\
\hline $\mathrm{U} 4$ & male & No & 4 months & Citrus + EPI \\
\hline Q3 & male & Yes LD & 3.5 years & Citrus + EPI \\
\hline U3 & female & No & 20 years & Citrus + EPI \\
\hline Q2 & male & Yes LD & 21 years & Citrus + EPI \\
\hline $\mathrm{U} 2$ & female & No & 4 years & Citrus \\
\hline $\mathrm{Q} 1$ & female & Yes MH & 1 year & Citrus \\
\hline $\mathrm{U} 1$ & female & No & 2 months & Citrus \\
\hline
\end{tabular}

Table 1: participant demographic information

LD = Learning Disability

$\mathrm{MH}=$ Mental Health

* EPI trained only in relation to this client

** 19 years in service 1 year qualified 